\title{
TINGKAT PENDAPATAN KELUARGA, POLA ASUH ORANG TUA, STIMULASI PERKEMBANGAN, DAN PERKEMBANGAN BALITA
}

\author{
Nurul Khairani $^{1}$, Sannisahhuri ${ }^{2}$, Fauziah Prasisti Yinisah ${ }^{3}$ \\ Program Studi S1 Kesehatan Masyarakat \\ STIKES Tri Mandiri Sakti Bengkulu \\ nurul.sulaksono@gmail.com ${ }^{1}$, sanisahhuri79@gmail.com²
}

\begin{abstract}
An important period in child development is toddlerhood. During this time, development of language skills, creativity, social awareness and others run very fast times and determines the next development and quality of human resources. The purpose of this research was to study the relationship between family income levels, parenting and developmental stimulation with development of toddlers aged 4-5 years in Dwi Wardani Kindergarten Bengkulu City. Type of this research was Survey Analytic with Cross Sectional design. Population of this study was all mothers with toddlers aged 4-5 years in Dwi Wardani Kindergarten Bengkulu City, as many as 32 mothers. Sample were taken using a Total Sampling amount of 32 mothers. Analysis were performed with univariate and bivariate analysis with Chi-Square test $\left(\chi^{2}\right)$. The results of this research revealed that of the 32 mothers there were 17 mothers $(53.1 \%)$ with low income levels, 24 mothers (75.0) who had democratic parenting, 16 mothers (50.0\%) who had often carried out developmental stimulation, 25 mother (78.1\%) who had toddlers with good development. There was no significant relationship between level of family income and development of toddlers, there was a significant relationship between parenting and development of toddlers with a category of close relationship, and there was a significant relationship between developmental stimulation and development of toddlers with a category of moderate relationship.
\end{abstract}

Keywords: Development Of Toddlers, Developmental Stimulation, Family Income Level, Parenting

\begin{abstract}
ABSTRAK
Periode penting dalam perkembangan anak adalah masa balita. Pada masa ini perkembangan kemampuan berbahasa, kreativitas, kesadaran sosial dan lain-lain berjalan sangat cepat dan menentukan perkembangan selanjutnya serta kualitas sumber daya manusia. Penelitian ini bertujuan untuk mempelajari hubungan antara tingkat pendapatan keluarga, pola asuh orang tua dan stimulasi perkembangan dengan perkembangan balita usia 4-5 tahun di PAUD Dwi Wardani Kota Bengkulu. Jenis penelitian ini adalah Survey Analitik dengan desain Cross Sectional. Populasi dalam penelitian ini adalah seluruh ibu yang memiliki balita usia 4-5 tahun di PAUD Dwi Wardani Kota Bengkulu tahun ajaran 2018/2019 sebanyak 32 ibu. Sampel sebanyak 32 ibu yang diambil dengan menggunakan teknik Total Sampling. Teknik analisis data dilakukan dengan analisis univariat dan bivariat dengan uji Chi-Square $\left(\chi^{2}\right)$. Hasil penelitian menunjukkan bahwa dari $32 \mathrm{ibu}$, terdapat $17 \mathrm{ibu}$ $(53,1 \%)$ dengan tingkat pendapatan rendah, $24 \mathrm{ibu}(75,0 \%)$ dengan pola asuh demokratis, $16 \mathrm{ibu}$ $(50,0 \%)$ sering melakukan stimulasi perkembangan, dan $25 \mathrm{ibu}(78,1 \%)$ yang memiliki balita dengan perkembangan sesuai dengan tahap perkembangannya. Tidak ada hubungan yang signifikan antara tingkat pendapatan keluarga dengan perkembangan balita, ada hubungan signifikan antara pola asuh orang tua dengan perkembangan balita dengan kategori hubungan erat, ada hubungan signifikan antara stimulasi perkembangan dengan perkembangan balita dengan kategori hubungan sedang.
\end{abstract}

Kata Kunci: Perkembangan Balita, Pola Asuh Orang Tua, Stimulasi Perkembangan, Tingkat Pendapatan Keluarga 


\section{PENDAHULUAN}

Periode penting dalam perkembangan anak adalah masa balita. Pada masa ini kebutuhan dasar yang akan mempengaruhi dan menentukan perkembangan selanjutnya. Pada masa balita ini perkembangan kemampuan berbahasa, kreativitas, kesadaran sosial dan lain-lain berjalan sangat cepat dan merupakan landasan perkembangan berikutnya. Perkembangan moral dan dasar-dasar kepribadian juga dibentuk pada masa ini, setiap kelainan atau penyimpangan sekecil apapun apabila tidak terdeteksi apalagi tidak ditangani dengan baik, akan mengurangi kualitas sumber daya manusia di kemudian hari (Soetjiningsih, 2013).

Menurut Soetjiningsih (2013), beberapa gangguan perkembangan anak antara lain gangguan bicara dan bahasa yang diperkirakan angka kejadiannya berkisar 1,0\%-32,0\%, cerebral palsy sekitar 1-5 per 1000 anak, down sindrom yaitu 1 per 1000 anak, retardasi mental sekitar 0,3\%-0,4\%, gangguan pemusatan perhatian dan hiperaktivitas sebesar 4,0\%-12,0\%. Untuk autis belum ada angka kejadian yang pasti, hanya dari pengamatan beberapa ahli didapatkan kecenderungan peningkatan kasus yang ditangani. Penelitian yang dilakukan di Jepang terhadap 21.610 anak yang diikuti sejak lahir sampai umur 3 tahun didapatkan 1,3 kasus autis per 1000 anak. Hasil yang serupa didapatkan di Swedia, yaitu sekitar 1 sampai 2 per 1000 anak menderita autis (Soetjiningsih, 2013).

Keadaan ekonomi keluarga erat hubungannya dengan belajar anak. Anak yang sedang belajar selain harus terpenuhi kebutuhan pokoknya, misalnya makan, minum, pakaian, perlindungan kesehatan, juga membutuhkan fasilitas belajar seperti ruang belajar, meja, kursi, penerangan, alat tulis menulis, buku dan lain-lain (Slameto, 2010).

Berdasarkan penelitian yang dilakukan oleh Sunanti dan Nurasih (2016) terhadap 78 balita usia 12-59 bulan di Desa Karayunan Kabupaten Majalengka, ada hubungan antara pendapatan orang tua dengan perkembangan balita usia 12-59 bulan.

Menurut Septiari (2012), pola asuh orang tua berdampak kepada anaknya. Pola asuh otoriter menyebabkan anak menjadi penakut, pencemas, menarik diri dari pergaulan, kurang adaptif, kurang tujuan, curiga kepada orang lain, dan mudah stress. Pola asuh permisif mengakibatkan anak agresif, tidak patuh pada orang tua, sok kuasa, dan. kurang mampu mengontrol diri. Pola asuh demokratis dapat mengakibatkan anak mandiri, mempunyai kontrol diri, mempunyai kepercayaan diri yang kuat, dapat berinteraksi dengan teman sebayanya dengan baik, mampu menghadapi stress, mempunyai minat terhadap hal-hal yang baru, kooperatif dengan orang dewasa, penurut, patuh, dan berorientasi pada prestasi.

Pola asuh yang diterapkan orang tua juga sangat berpengaruh terhadap perkembangan anak. Anak yang dibesarkan dengan pola pengasuhan otoriter cenderung bersifat curiga pada orang lain, merasa tidak bahagia dengan dirinya sendiri, merasa canggung berhubungan dengan teman sebaya, dan memiliki prestasi belajar yang rendah dibandingkan dengan anak- anak lain (Desmita, 2008). Anak yang dibesarkan dengan pola pengasuhan permisif anak cenderung kurang bertanggung jawab, mempunyai kendali emosi yang buruk, dan sering berprestasi rendah dalam melakukan sesuatu. Anak yang dibesarkan dengan pola pengasuhan yang demokratis mempunyai penyesuaian pribadi dan sosial yang yang lebih baik, anak lebih mandiri, serta bertanggung jawab (Soetjiningsih, 2013).

Berdasarkan penelitian yang dilakukan Kurniati dan Mardianti (2014), pada 35 Balita di Posyandu Arjuna RW VI Pos 3 Kelurahan Kemayoran Kecamatan Krembangan Surabaya, terdapat hubungan antara pola asuh orang dengan perkembangan balita dengan kategori hubungan yang kuat. Pola asuh yang baik sangat erat hubungannya dengan perkembangan anak yang baik dan sebaliknya pola asuh yang kurang baik 
membuat perkembangan anak kurang baik dalam tahap perkembangannya. Pola asuh yang baik merupakan pola asuh yang sesuai dengan tahap perkembangan anak (Sapril, Jamaluddin, dan Nurbaya, 2014).

Berdasarkan penelitian yang dilakukan Sumiyati dan Yuliani (2016) pada anak usia 4-5 tahun di Desa Karang Tengah Kecamatan Baturraden Kabupaten Banyumas, terdapat hubungan antara stimulasi perkembangan dengan perkembangan anak usia 4-5 tahun. Anak yang banyak mendapat stimulasi akan lebih cepat berkembang dari pada anak yang kurang atau bahkan tidak mendapat stimulasi. Semakin dini dan semakin lama stimulasi dilakukan, maka semakin besar manfaat bagi perkembangan seorang anak (Maryunani, 2010).

\section{METODE}

Jenis penelitian ini merupakan penelitian Survei Analitik dengan Desain penelitian adalah Cross Sectional. Penelitian telah dilaksanakan di PAUD Dwi Wardani
Kota Bengkulu pada tanggal 4-16 Februari 2019. Populasi dalam penelitian ini adalah seluruh ibu yang memiliki balita usia 4-5 tahun di PAUD Dwi Wardani Kota tahun ajaran 2018/2019 Kota Bengkulu sebanyak 32 ibu. Sampel sebanyak 32 ibu yang diambil menggunakan teknik Total Sampling. Data yang digunakan adalah data primer dan sekunder. Teknik analisis data dilakukan dengan analisis univariat dan analisis bivariat. Analisis bivariat menggunakan uji Chi-Square $\left(\chi^{2}\right)$. Untuk mengetahui keeratan hubungan menggunakan Contingency Coefficient (C).

\section{HASIL}

\section{Analisis Univariat}

Analisis univariat bertujuan untuk mengetahui distribusi frekuensi variabel bebas (tingkat pendapatan keluarga, pola asuh orang tua, dan stimulasi perkembangan) dan variabel terikat (perkembangan balita). Hasilnya adalah sebagai berikut :

Tabel 1. Distribusi Frekuensi Tingkat Pendapatan Keluarga di PAUD Dwi Wardani Kota Bengkulu

\begin{tabular}{|c|c|c|c|}
\hline No. & Tingkat Pendapatan Keluarga & Frekuensi & Persentase $(\%)$ \\
\hline 1. & Rendah & 17 & 53,1 \\
\hline 2. & Tinggi & 15 & 46,9 \\
\hline & Jumlah & 32 & 100,0 \\
\hline
\end{tabular}

Keterangan : Data Primer, 2019

Berdasarkan Tabel 1 diketahui bahwa dari 32 ibu di PAUD Dwi Wardani Kota Bengkulu, terdapat $17 \mathrm{ibu}(53,1 \%)$ memiliki tingkat pendapatan keluarga yang rendah dan
15 ibu (46,9\%) memiliki tingkat pendapatan keluarga yang tinggi.

Tabel 2. Distribusi Frekuensi Pola Asuh Orang Tua di PAUD Dwi Wardani Kota Bengkulu

\begin{tabular}{clccc}
\hline No. & \multicolumn{2}{c}{ Pola Asuh Orang Tua } & Frekuensi & Persentase (\%) \\
\hline 1 & Otoriter & 0 & 0,0 \\
2 & Permisif & & 8 & 25,0 \\
3 & Demokratis & & 24 & 75,0 \\
\hline \multicolumn{2}{r}{} & Total & $\mathbf{3 2}$ & $\mathbf{1 0 0 , 0}$ \\
\hline
\end{tabular}

Keterangan : Data Primer, 2019

Berdasarkan Tabel 2 diketahui bahwa dari 32 ibu di di PAUD Dwi Wardani Kota
Bengkulu, tidak terdapat ibu yang memiliki pola asuh otoriter, terdapat 8 ibu $(25,0 \%)$ 
yang memiliki pola asuh permisif dan $24 \mathrm{ibu}$ $75,0 \%$ ) yang memiliki pola asuh orang tua

demokratis.

Tabel 3. Distribusi Frekuensi Stimulasi Perkembangan di PAUD Dwi Wardani Kota Bengkulu

\begin{tabular}{ccccc}
\hline No. & & Stimulasi Perkembangan & Frekuensi & Persentase (\%) \\
\hline 1 & Jarang & 16 & 50,0 \\
2 & Sering & Total & 16 & 50,0 \\
\hline & & & $\mathbf{3 2}$ & $\mathbf{1 0 0 , 0}$ \\
\hline
\end{tabular}

Keterangan : Data Primer, 2019

Berdasarkan Tabel 3 diketahui bahwa dari 32 ibu di di PAUD Dwi Wardani Kota Bengkulu, terdapat 16 ibu $(50,0 \%)$ yang jarang melakukan stimulasi perkembangan pada anak dan 16 ibu $(50,0 \%)$ yang sering melakukan stimulasi perkembangan pada anak.

Tabel 4. Distribusi Frekuensi Perkembangan Balita di PAUD Dwi Wardani Kota Bengkulu

\begin{tabular}{clccc}
\hline No. & & Perkembangan Balita & Frekuensi & Persentase (\%) \\
\hline 1 & Menyimpang & 0 & 0,0 \\
2 & Meragukan & 7 & 21,9 \\
3 & Sesuai & 25 & 78,1 \\
\hline & & $\mathbf{3 2}$ & $\mathbf{1 0 0 , 0}$ \\
\hline
\end{tabular}

Keterangan : Data Primer, 2019

Berdasarkan Tabel 4 diketahui bahwa dari 32 ibu di PAUD Dwi Wardani Kota Bengkulu, tidak terdapat ibu yang memiliki perkembangan anak yang menyimpang, ada $7 \mathrm{ibu}(21,9 \%)$ yang memiliki anak dengan perkembangan meragukan. Ada $25 \mathrm{ibu}$ $(78,1 \%)$ yang memiliki anak dengan perkembangan yang sesuai dengan tahap perkembangannya.

\section{Analisis Bivariat}

Analisis bivariat bertujuan untuk mempelajari hubungan antara variabel bebas (tingkat pendapatan keluarga, pola asuh orang tua, dan stimulasi perkembangan) dengan variabel terikat (perkembangan balita). Hasilnya adalah sebagai berikut :

Tabel 5. Tabulasi Silang antara Tingkat Pendapatan Keluarga dengan Perkembangan Balita Usia 4-5 tahun

\begin{tabular}{|c|c|c|c|c|c|c|c|c|c|}
\hline \multirow{3}{*}{$\begin{array}{c}\text { Tingkat } \\
\text { Pendapatan } \\
\text { Keluarga }\end{array}$} & \multicolumn{4}{|c|}{ Perkembangan Balita } & \multirow{2}{*}{\multicolumn{2}{|c|}{ Total }} & \multirow{3}{*}{$\chi^{2}$} & \multirow{3}{*}{$\mathbf{p}$} & \multirow{3}{*}{$\mathbf{C}$} \\
\hline & \multicolumn{2}{|c|}{ Meragukan } & \multicolumn{2}{|c|}{ Sesuai } & & & & & \\
\hline & $\mathbf{F}$ & $\%$ & $\mathbf{F}$ & $\%$ & $\mathbf{F}$ & $\%$ & & & \\
\hline Rendah & 3 & 17,6 & 14 & 82,4 & 17 & 100,0 & & & \\
\hline Tinggi & 4 & 26,7 & 11 & 73,3 & 15 & 100,0 & - & 0,678 & 0,108 \\
\hline Total & 7 & 21,9 & 25 & 78,1 & 32 & 100,0 & & & \\
\hline
\end{tabular}

Keterangan : Data Primer, 2019

Berdasarkan Tabel 5 dapat diketahui bahwa dari $17 \mathrm{ibu}$ yang memiliki tingkat pendapatan keluarga rendah, terdapat $3 \mathrm{ibu}$ yang memiliki anak dengan perkembangan meragukan dan 14 ibu yang memiliki anak dengan perkembangan sesuai dengan tahap perkembangannya. Dari 15 ibu yang memiliki tingkat pendapatan tinggi, terdapat 4 ibu yang memiliki anak dengan perkembangan yang meragukan dan $11 \mathrm{ibu}$ yang memiliki anak dengan perkembangan yang sesuai dengan tahap perkembangannya.

Untuk mengetahui hubungan antara tingkat pendapatan keluarga dengan 
perkembangan balita usia 4-5 tahun di PAUD Dwi Wardani Kota Bengkulu digunakan uji Chi-Square (Fisher's Exact Test). Hasil uji Fisher's Exact Test didapat nilai exact.sig $(\mathrm{p})=0,678$. Jadi tidak ada hubungan yang signifikan antara tingkat pendapatan keluarga dengan perkembangan balita usia 4-5 tahun di PAUD Dwi Wardani Kota Bengkulu. Hasil uji Contingency Coeffiecient didapatkan nilai $\mathrm{C}=0,108$.

Tabel 6. Tabulasi Silang antara Pola Asuh Orang Tua dengan Perkembangan Balita Usia 4-5 Tahun

\begin{tabular}{|c|c|c|c|c|c|c|c|c|c|}
\hline \multirow{3}{*}{$\begin{array}{l}\text { Pola Asuh } \\
\text { Orang Tua }\end{array}$} & \multicolumn{4}{|c|}{ Perkembangan Balita } & \multirow{2}{*}{\multicolumn{2}{|c|}{ Total }} & \multirow{3}{*}{$\chi^{2}$} & \multirow{3}{*}{$\mathbf{p}$} & \multirow{3}{*}{$\mathbf{C}$} \\
\hline & \multicolumn{2}{|c|}{ Meragukan } & \multicolumn{2}{|c|}{ Sesuai } & & & & & \\
\hline & $\mathbf{F}$ & $\%$ & $\mathbf{F}$ & $\%$ & $\mathbf{F}$ & $\%$ & & & \\
\hline Permisif & 6 & 75,0 & 2 & 25,0 & 8 & 100,0 & & & \\
\hline Demokratis & 1 & 4,2 & 23 & 95,8 & 24 & 100,0 & - & 0,000 & 0,596 \\
\hline Total & 7 & 21,9 & 25 & 78,1 & 32 & 100,0 & & & \\
\hline
\end{tabular}

Keterangan : Data Primer, 2019

Berdasarkan Tabel 6 dapat diketahui bahwa dari 8 ibu dengan pola asuh permisif, terdapat 6 ibu yang memiliki anak dengan perkembangan meragukan dan 2 ibu yang memiliki anak dengan perkembangan yang sesuai dengan tahap perkembangannya. Dari 24 ibu dengan pola asuh demokratis, terdapat 1 ibu yang memiliki anak dengan perkembangan meragukan dan 23 ibu yang memiliki anak dengan perkembangan yang sesuai dengan tahap perkembangannya di PAUD Dwi Wardani Kota Bengkulu.
Untuk mengetahui hubungan antara pola asuh orang tua dengan perkembangan balita usia 4-5 tahun di PAUD PAUD Dwi Wardani Kota Bengkulu digunakan uji ChiSquare (Fisher's Exact Test). Hasil uji Fisher's Exact Test didapat nilai exact.sig $(\mathrm{p})=0,000$. Jadi, ada hubungan antara pola asuh orang tua dengan perkembangan balita usia 4-5 tahun di PAUD Dwi Wardani Kota Bengkulu. Hasil uji Contingency Coefficient di dapatkan nila $\mathrm{C}=0,596$. Artinya kategori keeratan hubungan antara pola asuh orang tua dengan perkembangan balita adalah erat.

Tabel 7. Tabulasi Silang antara Stimulasi Perkembangan dengan Perkembangan Balita Usia 4-5 Tahun

\begin{tabular}{|c|c|c|c|c|c|c|c|c|c|}
\hline \multirow{3}{*}{$\begin{array}{c}\text { Stimulasi } \\
\text { Perkembangan }\end{array}$} & \multicolumn{4}{|c|}{ Perkembangan Balita } & \multirow{2}{*}{\multicolumn{2}{|c|}{ Total }} & \multirow{3}{*}{$\chi^{2}$} & \multirow{3}{*}{$\mathbf{p}$} & \multirow{3}{*}{$\mathbf{C}$} \\
\hline & \multicolumn{2}{|c|}{ Meragukan } & \multicolumn{2}{|c|}{ Sesuai } & & & & & \\
\hline & $\mathbf{F}$ & $\%$ & $\mathbf{F}$ & $\%$ & $\mathbf{F}$ & $\%$ & & & \\
\hline Jarang & 7 & 43,8 & 9 & 56,3 & 16 & 100,0 & & & \\
\hline Sering & 0 & 0,0 & 16 & 100,0 & 16 & 100,0 & - & 0,007 & 0,468 \\
\hline Total & 7 & 21,9 & 25 & 78,1 & 32 & 100,0 & & & \\
\hline
\end{tabular}

Keterangan : Data Primer, 2019

Berdasarkan Tabel 7 dapat diketahui bahwa dari $16 \mathrm{ibu}$ yang jarang melakukan stimulasi perkembangan pada anaknya, terdapat $7 \mathrm{ibu}$ yang memiliki anak dengan perkembangan meragukan dan 9 ibu yang memiliki anak dengan perkembangan sesuai dengan tahap perkembangannya. Dari $16 \mathrm{ibu}$ yang sering melakukan stimulasi perkembangan kepada anaknya, tidak terdapat anak dengan perkembangan yang meragukan dan terdapat 16 ibu yang memiliki anak dengan perkembangan yang sesuai dengan tahap perkembangannya di PAUD Dwi Wardani Kota Bengkulu.

Untuk mengetahui hubungan stimulasi perkembangan dengan perkembangan balita usia 4-5 tahun di PAUD Dwi Wardani Kota Bengkulu digunakan uji Chi-Square (Fisher's Exact Test). Hasil uji Fisher's Exact Test didapat nilai exact.sig $(\mathrm{p})=0,007$. Jadi ada hubungan antara stimulasi perkembangan dengan perkembangan balita 
usia 4-5 tahun di PAUD Dwi Wardani Kota Bengkulu. Hasil uji Contingency Coefficient didapatkan nilai $\mathrm{C}=0,468$. Artinya kategori keeratan hubungan antara stimulasi perkembangan dengan perkembangan balita adalah erat.

\section{PEMBAHASAN}

\section{Hubungan antara Pendapatan Keluarga dengan Perkembangan Balita Usia 4-5 Tahun}

Berdasarkan hasil analisis bivariat, dari 17 ibu yang memiliki tingkat pendapatan keluarga yang rendah, terdapat $14 \mathrm{ibu}$ yang memiliki anak dengan perkembangan sesuai dengan tahap perkembangannya. Hal ini dikarenakan ibu sering memberikan stimulasi pada anak seperti sering mengajak anak berbicara dan menemani anak belajar. Anak memiliki motivasi belajar yang tinggi dan interaksi antara orang tua dan anak yang baik.

Dari 15 ibu yang memiliki tingkat pendapatan tinggi, terdapat 4 ibu yang memiliki anak dengan perkembangan yang meragukan. Hal ini disebabkan karena kesibukan orang tua (ibu dan ayah samasama bekerja) sehingga anak diasuh oleh pengasuh yang membuat interaksi antara anak dengan orang tua menjadi berkurang dan anak kurang mendapatkan perhatian dari orang tuanya. Sebagian ibu juga mengatakan bahwa anaknya memiliki penyakit, seperti gangguan pencernaan, tipes, dan sering demam.

Berdasarkan hasil uji statistik ChiSquare menunjukkan bahwa tingkat pendapatan keluarga tidak berhubungan dengan perkembangan balita usia 4-5 tahun di PAUD Dwi Wardani Kota Bengkulu. Artinya tingkat pendapatan keluarga tidak menentukan perkembangan balita usia 4-5 tahun di PAUD Dwi Wardani Kota Bengkulu.

Penelitian ini tidak sejalan dengan teori yang dikemukakan oleh Soetjiningsih (2013) yang menyatakan bahwa pendapatan berpengaruh terhadap perkembangan anak.
Penelitian ini juga tidak sejalan dengan penelitian yang dilakukan oleh Sunanti dan Nurasih (2016) terhadap 78 orang balita usia 12-59 bulan di Desa Karayunan Kabupaten Majalengka yang menunjukkan bahwa ada hubungan antara pendapatan orang tua dengan perkembangan balita usia 12-59 bulan.

\section{Hubungan antara Pola Asuh Orang Tua dengan Perkembangan Balita Usia 4-5 Tahun}

Berdasarkan hasil analisis bivariat, dari 8 ibu yang memiliki anak dengan pola asuh permisif, terdapat 2 ibu yang memilik anak dengan perkembangan yang sesuai dengan tahap perkembangannya. Hal ini dikarenaka meskipun orang tua dengan pola asuh permisif, namun ibu selalu memberikan stimulasi perkembangan seperti mengajari anak belajar di rumah, mengajak anak berbicara, dan ibu sudah mengetahui tentang pemenuhan gizi yang dibutuhkan oleh anaknya yang dapat menunjang perkembangan anaknya.

Dari 24 ibu yang memiliki anak dengan pola asuh demokratis, terdapat $1 \mathrm{ibu}$ yang memilik anak dengan perkembangan yang meragukan. Hal ini disebabkan kurangnya perhatian orang tua terhadap perkembangan anaknya dikarenakan mereka sibuk bekerja sehingga perkembangan balita kurang terkontrol dengan baik.

Berdasarkan hasil uji statistik ChiSquare menunjukkan bahwa ada hubungan yang signifikan antara pola asuh orang tua dengan perkembangan balita usia 4-5 tahun di PAUD Dwi Wardani Kota Bengkulu. Artinya pola asuh orang tua menentukan perkembangan balita usia 4-5 tahun di PAUD Dwi Wardani Kota Bengkulu. Penelitian ini sejalan dengan teori yang dikemukakan oleh Soetjiningsih (2013) bahwa pola asuh orang tua sangat berpengaruh terhadap perkembangan anak.

Hasil penelitian ini juga sejalan dengan penelitian yang dilakukan oleh Sapril, Jamaluddin, dan Nurbaya (2014) terhadap 42 orang anak usia 3-5 tahun di TK Islam 
Qalbin Salim Makasar yang menunjukkan bahwa terdapat hubungan antara pola asuh orang tua terhadap perkembangan anak dengan kategori hubungan yang kuat. Pola asuh yang baik sangat erat hubungannya dengan perkembangan anak yang baik dan sebaliknya pola asuh yang kurang baik membuat perkembangan anak kurang baik.

\section{Hubungan antara Stimulasi Perkembangan dengan Perkembangan Balita Usia 4-5 Tahun}

Berdasarkan hasil analisis bivariat, dari 16 ibu yang jarang memberikan stimulasi perkembangan kepada anaknya, terdapat 9 ibu yang memiliki anak dengan perkembangan yang sesuai dengan tahap perkembangannya. Hal ini karena meskipun ibu jarang memberikan stimulasi, tetapi balita sering bermain dengan kakaknya di rumah dan diajari oleh kakak-kakaknya.

Dari 16 ibu yang sering memberikan stimulasi perkembangan kepada anaknya, tidak terdapat anak dengan perkembangan meragukan. Hal ini menunjukkan bahwa semakin sering stimulasi dilakukan, maka perkembangan anak akan semakin sesuai dengan tahap perkembangannya.

Berdasarkan hasil uji statistik ChiSquare menunjukkan bahwa ada hubungan yang signifikan antara stimulasi perkembangan dengan perkembangan balita usia 4-5 tahun di PAUD Dwi Wardani Kota Bengkulu. Artinya stimulasi perkembangan menentukan perkembangan balita usia 4-5 tahun di PAUD Dwi Wardani Kota Bengkulu.

Hal tersebut sesuai dengan teori yang dikemukakan oleh Maryunani (2010) bahwa anak yang banyak mendapatkan stimulasi akan lebih cepat berkembang daripada anak yang kurang atau bahkan tidak mendapatkan stimulasi. Semakin dini dan semakin lama stimulasi dilakukan, maka semakin besar manfaat bagi perkembangan seorang anak.

Hal ini sejalan dengan hasil penelitian Sumiyati dan Yuliani (2016) terhadap 41 anak yang berusia 4-5 tahun di Desa Karang Tengah Kecamatan Baturraden Kabupaten
Banyumas yang menunjukan bahwa terdapat hubungan antara stimulasi perkembangan dengan perkembangan anak dengan kategori hubungan yang kuat.

\section{KESIMPULAN}

Berdasarkan hasil penelitian tentang "Hubungan antara Tingkat Pendapatan Keluarga, Pola Asuh Orang Tua, dan Stimulasi Perkembangan dengan Perkembangan Balita Usia 4-5 Tahun di PAUD Dwi Wardani Kota Bengkulu", dapat disimpulkan sebagai berikut:

1. Dari 32 ibu, terdapat 17 ibu $(53,1 \%)$ yang memiliki tingkat pendapatan keluarga rendah di PAUD Dwi Wardani Kota Bengkulu.

2. Dari $32 \mathrm{ibu}$, terdapat $24 \mathrm{ibu}(75,0 \%)$ memiliki pola asuh demokratis di PAUD Dwi Wardani Kota Bengkulu.

3. Dari $32 \mathrm{ibu}$, terdapat $16 \mathrm{ibu}(50,0 \%)$ yang sering melakukan stimulasi di PAUD Dwi Wardani Kota Bengkulu

4. Dari $32 \mathrm{ibu}$, terdapat $25 \mathrm{ibu}(78,1 \%)$ yang memiliki perkembangan anak yang sesuai dengan tahap perkembangannya di PAUD Dwi Wardani Kota Bengkulu

5. Tidak ada hubungan yang signifikan antara tingkat pendapatan keluarga dengan perkembangan balita usia 4-5 tahun di PAUD Dwi Wardani Kota Bengkulu

6. Ada hubungan yang signifikan antara pola asuh orang tua dengan perkembangan balita usia 4-5 tahun di PAUD Dwi Wardani Kota Bengkulu dengan kategori hubungan erat.

7. Ada hubungan yang signifikan antara stimulasi perkembangan dengan perkembangan balita usia 4-5 tahun di PAUD Dwi Wardani Kota Bengkulu dengan kategori hubungan erat.

\section{DAFTAR PUSTAKA}

Desmita, R. (2008). Psikologi Perkembangan. Bandung: PT. Remaja Rosdakarya.

Kurniawati, L. D. dan Mardiyanti, I. (2014). Pola Asuh Orang Tua Mempengaruhi 
Perkembangan Balita Di Posyandu Arjuna RW IV Pos 3 Kelurahan Kemayoran Kecamatan Krembangan Surabaya, Jurnal Ilmiah Kesehatan, 7 (1). Diunduh dari: http://journal.unusa.ac.id/index.php/jhs /article/viewFile/ 47/43.

Maryunani, A. (2010). Ilmu Kesehatan Anak dalam Kebidanan. Jakarta: CV. Trans Info.

Sapril, R. A., Jamaluddin, M., dan Nurbaya, S. (2014). Pola Asuh Orang Tua dengan Perkembangan Anak Usia 3-5 Tahun di TK Islam Qalbin Salim Makassar, Jurnal Ilmiah Kesehatan Diagnosis, 3 (3), pp. 50-54. Diunduh dari

http://ejournal.stikesnh.ac.id/index.php /jikd/article/view/541.

Septiari, B.B. (2012). Mencetak Balita Cerdas dan Pola Asuh Orang Tua. Yogyakarta: Nuha Medika.

Slameto. (2010). Belajar dan Faktor-Faktor yang Mempengaruhinya. Jakarta: Rineka Cipta.
Soetjiningsih. (2013). Tumbuh Kembang Anak Edisi 1. Jakarta: EGC.

Sumiyati dan Yuliani, D. R. (2016). Hubungan Stimulasi dengan Perkembangan Anak Usia 4-5 Tahun di Desa Karang Tengah Kecamatan Batur Raden Kabupaten Banyumas, Jurnal Link, 12 (01), pp. 34-38. Diunduh dari http://ejournal.poltekkessmg.ac.id/ojs/index.php/link/article/vie w/450.

Sunanti F. dan Nurasih. (2016). Karakteristik Orang Tua dan Perkembangan Balita Usia 12-59 Bulan, Jurnal Care, 4 (3), pp. 50-61. Diunduh dari: https://jurnal.unitri.ac.id/index.php/car e/article/view/434.

Yuniarti, S. (2015). Asuhan Tumbuh Kembang Neonatus, Bayi-Balita \& Anak Pra-Sekolah. Bandung: PT. Refika Aditama. 